\section{0 \\ EDITOR'S \\ CHOICE}

\title{
Worldwide evidence-based medicine activities
}

\section{Richard Saitz}

\section{$10.1136 / \mathrm{ebm} 1172$}

Editor, Evidence-based Medicine

Section of General Internal Medicine, Boston Medical Center, Boston University Schools of Medicine and Public Health, Boston, Massachusetts, USA

Correspondence to

\section{Richard Saitz}

Section of General Internal Medicine, Boston Medical Center, Boston University Schools of Medicine and Public Health, 801 Massachusetts Avenue, 2nd floor (Crosstown 2), Boston, MA 02118-2335, USA; rsaitz@bmjgroup.com

Published Online First

12 January 2011
Evidence-Based Medicine (EBM) serves at least two major communities - those teaching and studying evidencebased medicine (EBM) itself (and producing evidence), and those consuming evidence to improve patient care. Two recent developments of interest to both audiences are worth noting.

First, on 1 and 2 November, 2010, the British Medical Journal (BMJ) Evidence Centre and the Centre for Evidence-Based Medicine, Oxford University held an international conference ('evidence2010 Transforming Healthcare') in London. Although this was not a conference of a particular professional society nor was it an annual event (though it may be in the future), the conference was well-attended by a wide range of evidence producers and consumers from around the world. As a whole the participants had refreshing views about evidence-based medicine (EBM). They were neither 'for it' nor 'against it.' They understood that evidence-based medicine (EBM) was complex, has its place, has promised much and has delivered on much of that promise, but also faces many challenges, particularly in the area of how best to apply evidence in practice.

Many of the discussions were quite memorable, and I will mention only a few here (also see http://www. evidence2010.com). The editors of the Lancet and BMJ spoke, and debated, the future of medical publishing. One prediction was the greater accessibility of medical evidence, particularly online. That future, along with greater registration of clinical trials, will be welcome, because as was pointed out by another speaker, systematic reviews can be misleading when studies are done but never published. Victor Montori discussed the complicated work of being a patient with several chronic diseases and the challenges of applying evidence for specific diseases and interventions when caring for such patients. Although there was much discussion about how evidence is often not translated into practice, Bill Summerskill, when talking about a study that eventually leads to practice change, said "you may never actually be sure when that seed is planted and when it blossoms." That observation is one for implementation researchers to confirm and learn from. I cannot convey the genuine excitement that was evident among conference participants that they were taking part in an important event in the history of evidencebased medicine (EBM).

The other activity relevant for evidence-based medicine (EBM) as a field is the establishment of an international organisation called the International Society for Evidence-based Health Care. The mission is to develop and encourage research in evidence-based healthcare and to promote and provide professional and public education in the field. The society published its first newsletter (available at http://ebm.mcmaster.ca/), and it plans to hold meetings and disseminate evidence-based healthcare education via workshops and educational materials, and to promote research. It will no doubt be of interest to see how the society coalesces and finds its place in the world of professional societies.

To me, these developments indicate that despite, or perhaps because of the many challenges faced by evidence-based medicine (EBM) practitioners, teachers and researchers, evidence-based medicine (EBM) is alive, well and even thriving. I expect $E B M$ (the journal) will continue to serve this community well, and I welcome input from you on how it can best do so. 